\title{
Aplikasi Perhitungan Persediaan Bahan Baku dengan Metode Economic Order Quantity Berdasarkan Varian Produk
}

\author{
(Studi Kasus: CV Dwi Sumber, Semarang)
}

\author{
Rianti Rahmawati, Anak Agung Gde Agung, Fitri Sukmawati \\ Program Studi D3 Komputerisasi Akuntansi \\ Fakultas Ilmu Terapan, Universitas Telkom \\ Indonesia \\ riantirahmawati8@gmail.com, agung@tass.telkomuniversity.ac.id, fitri_unibi@yahoo.com
}

\begin{abstract}
CV Dwi Sumber is one of manufacture company which handles sales with variant product. Recording process of raw materials from the warehouse until production process was done manually. The company ordered raw material with the same amount without checking the stock quantity available in the warehouse. For every order, the company must pay order fee. Transactions record were also done manually so it was not directly reduce the stock of raw materials in the warehouse. This accumulated to overstock in the warehouse. This application used Economic Order Quantity (EOQ) to calculate optimal raw material order so it can reduce order fee. This application can also record transaction, automatically reduce stock in the warehouse, calculate safety stock in the warehouse so management can decide when they have to reorder the raw material. Transaction record can be viewed as accounting journal and general ledger. This application is built using PHP programming language and MySQL database.
\end{abstract}

Keywords-Safety Stock; Reorder Point;Economic Order Quantity; CV Dwi Sumber

\section{PEndahuluan}

CV Dwi Sumber adalah salah satu perusahaan manufaktur yang menangani penjualan dengan menawarkan varian produk pembuatan. Perusahaan ini berlokasi di Semarang, Jawa Tengah. Terdapat tiga jenis bahan baku utama yang digunakan yaitu plastik transaparan, plastik mika, dan plastik warna (AECE).

CV Dwi Sumber memproduksi tiga varian produk diantaranya map ijazah, sampul rapot, dan sampul SPP. Produksi rutin yang dilakukan dalam setiap harinya sebesar
500 buah produk. Untuk memenuhi kebutuhan bahan baku produksi, CV Dwi Sumber menetapkan beberapa supplier. Hal ini dimaksudkan agar tidak ada terjadi kekosongan bahan baku saat produksi berlangsung. Dalam setiap bulannya perusahaan dapat menjual produk sejumlah 15.000 produk.

Varian produk yang ditawarkan perusahaan menggunakan bahan baku yang berbeda-beda. Produk map ijazah menggunakan dua jenis bahan baku yaitu, plastik transparan dan AECE. Produk sampul rapot dan sampul SPP hanya menggunakan bahan baku plastik mika. Banyaknya bahan baku yang digunakan dalam satu varian produk mengakibatkan pengendalian salah satu persediaan bahan baku tidak efektif,yang dapat mengakibatkan persediaan bahan baku berlebih.

Perusahaan melakukan pembelian bahan baku sebanyak tiga kali dalam sebulan. Setiap kali pemesanan, perusahaan harus membayar biaya pemesanan. Saat ini, pemesanan bahan baku dilakukan dengan jumlah yang sama tanpa mengecek jumlah persediaan bahan baku yang berada digudang. Pencatatan transaksi juga masih dilaksanakan secara manual sehingga tidak langsung mengurangi stok bahan baku yang ada di gudang. Hal ini menyebabkan sering terjadinya penumpukan bahan baku.

Solusi yang diusulkan melalui penelitian ini adalah dengan membangun aplikasi yang dapat meminimalkan biaya persediaan dengan menggunakan metode Economic Order Quantity (EOQ). Dengan menerapkan EOQ, perusahaan dapat menghitung jumlah pemesanan optimal sehingga mengurangi biaya pemesanan dan penyimpanan. Perusahaan juga dapat mengetahui jumlah persediaan pengaman (safety stock) dan kapan harus melakukan pemesanan kembali (reorder point). Selain itu, aplikasi ini mencatat setiap transaksi yang terjadi dalam perusahaan, 
menampilkan transaksi tersebut ke dalam laporan akuntansi berupa jurnal dan buku besar.

\section{TINJAUAN PUSTAKA}

\subsection{Penelitian Sebelumnya}

Nunung Nurhasanah, dkk. menerapkan model EOQ untuk menentukan biaya pemesanan optimal untuk pembelian bahan baku pada perusahaan es Chika [1]. Eyverson dalam penelitiannya menentukan jumlah optimal dalam pembelian bahan baku (EOQ) untuk perusahaan roti Lianli di Manado [2]. Widi Astuti membandingkan perhitungan persediaan bahan baku antara metode EOQ dan konvensional pada perusahaan kopi di Singaraja, Bali [3]. Intan dalam penelitiannya menyimpulkan bahwa peramalan dan metode EOQ dapat menghemat biaya dalam pemesanan bahan baku [4].

\subsection{Metode Waterfall}

Pengembangan aplikasi dilakukan dengan menggunakan metode Waterfall. Tahap tersebut biasa disebut sebagai proses System Development Life Cycle (SDLC) yang berfungsi untuk menggambarkan tahapan-tahapan utama dalam mengembangkan sistem-sistem perangkat lunak. Model waterfall menyediakan pendekatan secara terurut dimulai dari analisis, desain, pengodean, dan penggujian. [5].

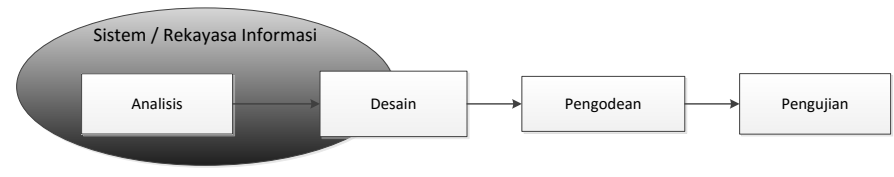

Gambar 1 Model Waterfall

\subsection{Akuntansi}

Secara umum akuntansi merupakan suatu sistem informasi yang digunakan untuk mengubah data dari transaksi menjadi informasi keuangan. Proses akuntansi meliputi kegiatan mengidentifikasi, mencatat, dan menafsirkan, mengomunikasikan peristiwa ekonomi dari sebuah organisasi kepada pemakai informasinya. Proses akuntansi menghasilkan informasi keuangan. Semua proses tersebut diselenggarakan secara tertulis dan berdasarkan bukti transaksi yang juga harus tertulis [8]. Pencatatan dalam akuntansi diwujudkan dengan jurnal.

\subsection{Persediaan}

Persediaan merupakan salah satu asset yang dimiliki perusahaan untuk diolah dari setiap kebutuhan barang baik barang mentah, barang setengah jadi, dan barang jadi agar selalu tersedia. Agar persediaan dalam kondisi baik dan stabil maka pihak perusahaan harus menerapkan konsep persediaan yang realistis dan dapat diterima oleh berbagai pihak. Dalam jumlah persediaan, setiap perusahaan memiliki jumlah berbeda-beda, dan jumlah itu disesuaikan dengan kondisi yang diinginkan. Pada perusahaan tertentu, kadang- kadang persediaan menggambarkan $70 \%$ dari keseluruhan aktiva lancar [6].

\subsection{Bahan Baku}

Bahan baku merupakan bahan langsung, yaitu bahan yang membentuk suatu kesatuan yang tidak terpisahkan dari produk jadi. Bahan baku adalah bahan utama atau bahan pokok dan merupakan komponen utama dari suatu produk. Bahan baku biasanya mudah ditelusuri dalam suatu produk dan harganya relative tinggi dibandingkan dengan bahan pembantu [7].

\subsection{Metode Economic Order Quantity}

EOQ atau kuantitas pesanan ekonomis adalah suatu metode untuk menentukan berapa jumlah pesanan yang paling ekonomis untuk satu kali pesan [6].Berikut cara menghitung EOQ [9].

$E O Q=\sqrt{\frac{2 P R}{C}}$

Keterangan :

EOQ = jumlah persediaan yang ekonomis

$\mathrm{R}=$ Pembelian bahan baku selama periode tertentu

$\mathrm{P} \quad=$ Biaya pemesanan

$\mathrm{C} \quad=$ Biaya penyimpanan per unit per tahun

Total biaya persediaan atau Total Inventory Cost (TIC) dapat dihitung dengan menggunakan berikut[9].

$T I C=\left[\frac{Q}{2} x C\right]+\left[\frac{R}{Q} x S\right]$

Keterangan :

TIC = Total biaya persediaan

$\mathrm{Q}=$ Jumlah pembelian dalam sekali pesan

$\mathrm{R}=$ = Pembelian bahan baku selama satu periode

$\mathrm{S} \quad=$ Biaya sekali pesan

\subsection{Persediaan Pengaman (Safety Stock)}

Safety Stock merupakan kemampuan perusahaan untuk menciptakan kondisi persediaan yang selalu aman atau penuh pengamanan dengan harapan perusahaan tidak akan pernah mengalami kekurangan persediaan[6].Berikut cara menghitung safety stock[6].

$$
\text { Safety Stock }=(Q \text { maks }-Q r)
$$

Keterangan :

Qmaks = Pemakaian maksimal

Qr $\quad=$ Pemakaian rata-rata

\subsection{Reorder Point}

Reorder Point adalah titik dimana suatu perusahaan harus memesan barang atau bahan guna menciptakan kondisi persediaan yang terus terkendali [6].Berikut cara menghitung reorder point [6]. 


\section{Reorder Point $=Q r+$ safety stock}

\subsection{Flowchart}

Flowchart atau bagan alir merupakan teknik analitis yang digunakan untuk menjelaskan aspek-aspek sistem informasi secara jelas, tepat, dan logis. Flowchart atau bagan alir menggunakan serangkaian simbol standar untuk menguraikan prosedur pengolahan transaksi yang digunakan oleh sebuah perusahaan, sekaligus menguraikan aliran data dalam sebuah sistem [10].

\section{PEMBAHASAN}

\subsection{Proses Usulan Perhitungan EOQ}

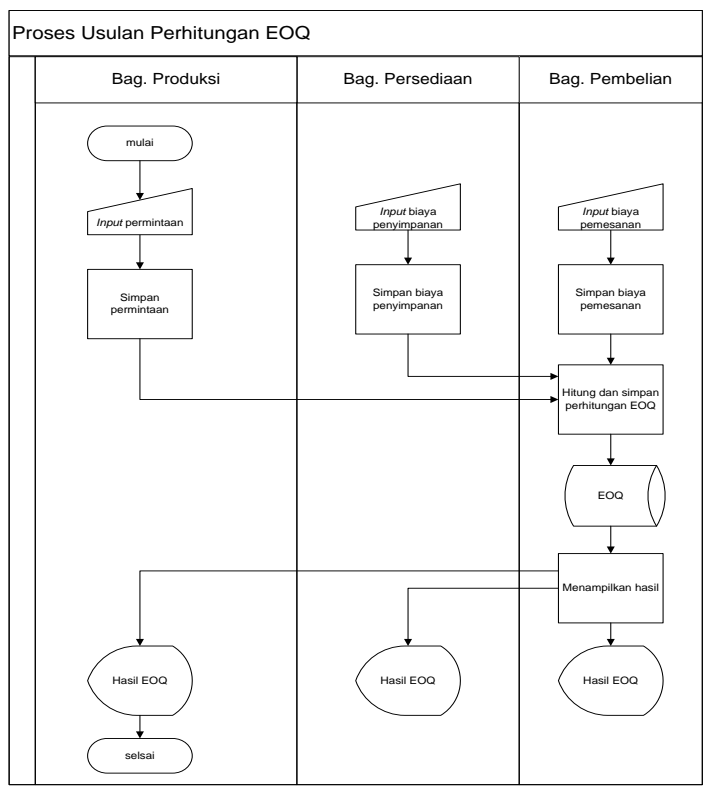

Gambar 2 Proses Usulan Perhitungan EOQ

Flowchart sistem yang diusulan pada proses perhitungan EOQ dapat dilihat pada Gambar 2.

\subsection{Data Flow Diagram (DFD) Level 0}

Data Flow Diagram (DFD) secara grafis menjelaskan arus data dalam sebuah organisasi.

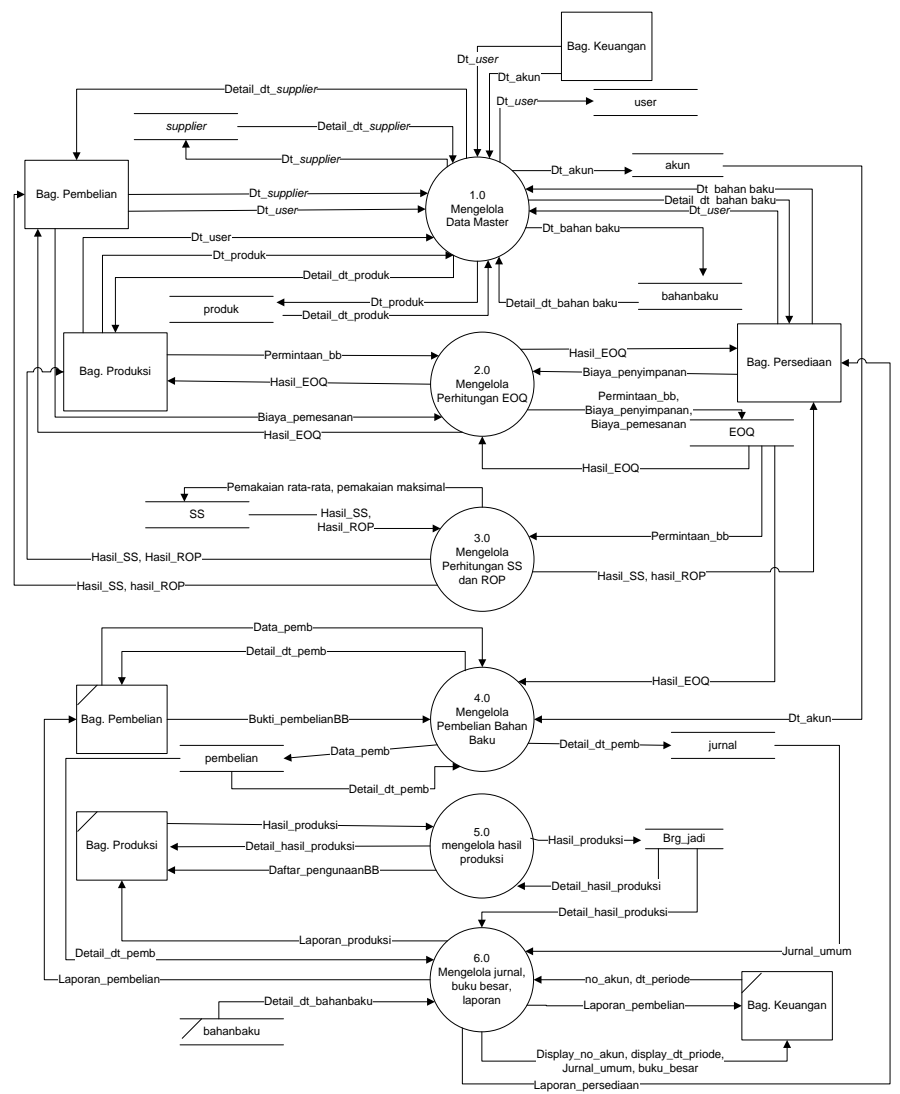

Gambar 3 Data Flow Diagram (DFD) Level 0

Teknik ini digunakan untuk mendokumentasikan sistem yang digunakan sekarang dan untuk merencanakan serta mendesain sistem yang baru[10]. Pada Gambar 3 terdapat enam bagian proses utama yaitu, proses data master, mengelola hasil produksi, perhitungan EOQ, perhitungan SS_ROP, pembelian bahan baku, dan mengelola jurnal dan buku besar.

\subsection{Entity Relationship Diagram (ERD)}

Entity Relationship Diagram (ERD) dikembangkan berdasarkan teori himpunan dalam bidang matematika. ERD digunakan untuk pemodelan basis data relasional [10].Berikut adalah model perancangan basis data yang digunakan pada Aplikasi Perhitungan Persediaan Bahan Baku Dengan Metode Economic Order Quantity Berdasarkan Varian Produk. 


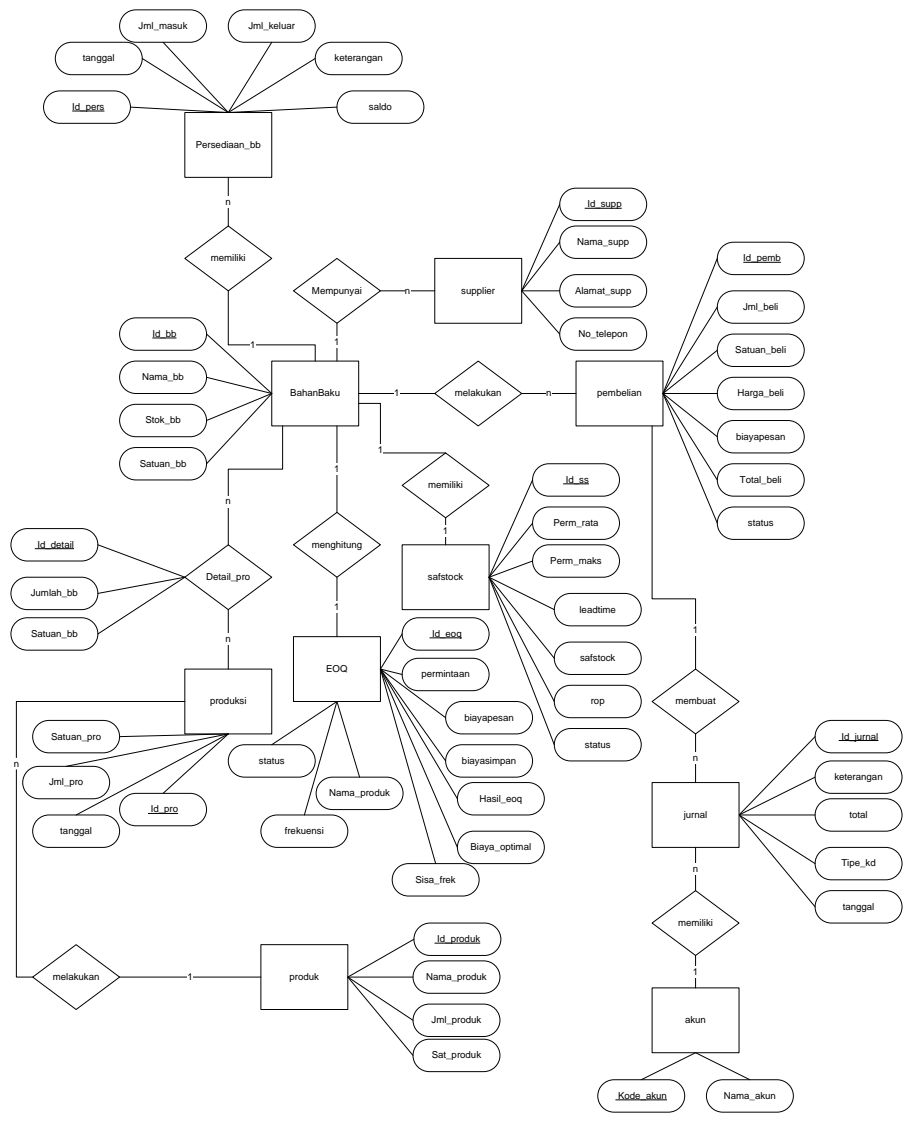

Gambar 4 Entity Relationship Diagram (ERD)

\subsection{Basis Data}

Aplikasi ini dibangun menggunakan database MySQL. Terdapat 12 tabel yang digunakan dalam pembuatan aplikasi ini.

Tabel 1 Daftar Tabel pada Basisdata

\begin{tabular}{|c|l|}
\hline No & \multicolumn{1}{|c|}{ Nama Tabel } \\
\hline 1 & akun \\
\hline 2 & bahanb \\
\hline 3 & detail_pro \\
\hline 4 & eoq \\
\hline 5 & jurnal \\
\hline 6 & pembelian \\
\hline 7 & persediaan_bb \\
\hline 8 & produk \\
\hline 9 & produksi \\
\hline 10 & safstock \\
\hline 11 & supplier \\
\hline
\end{tabular}

\begin{tabular}{|c|l|}
\hline No & \multicolumn{1}{|c|}{ Nama Tabel } \\
\hline 12 & user \\
\hline
\end{tabular}

\subsection{Pengujian Aplikasi}

Pengujian dilakukan dengan melibatkan pihak pengguna pada tempat studi kasus, untuk menguji fungsionalitas aplikasi dan kehandalannya. Terdapat Berikut beberapa skenario pengujian fungsionalitas utama yang dilakukan.

1. Pengujian input permintaan.

Bagian produksi memasukkan data berupa periode yang akan berlaku untuk EOQ tersebut. Memasukkan nama produk, id bahan baku, dan jumlah permintaan. Sesuai dengan data diatas data dapat tersimpan kedalam file EOQ.

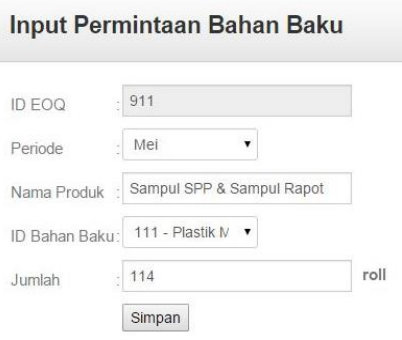

Gambar 5 Pengujian Input Permintaan

2. Pengujianinput biaya

Untuk fungsionalitas ini terdapat dua user yang terkait yaitu bagian persediaan dan bagian pembelian. Bagian persediaan akan memasukkan biaya penyimpanan bahan baku. Bagian pembelian akan memasukkan biaya pemesanan bahan baku. Memasukkan data biaya tersebut dilakukan masing-masing user sesuai dengan hak akses sistem user.
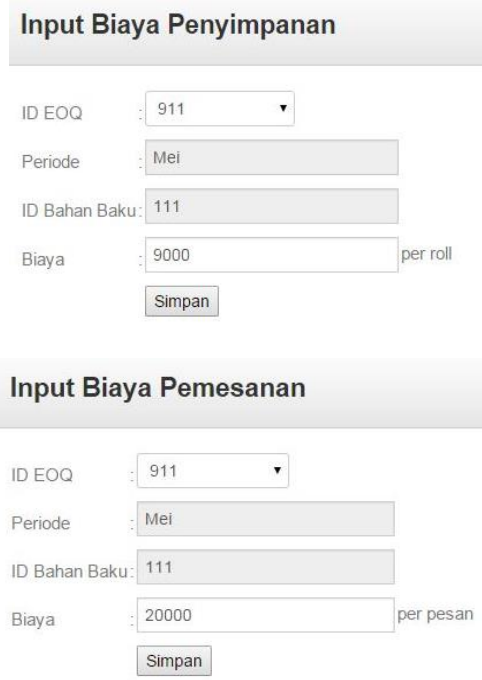

Gambar 6 Pengujian Input Biaya 


\section{Pengujian hasil EOQ}

Saat semua data masukan data permintaan dan data biaya-biaya telah dimasukkan oleh masing-masing user. Fungsionalitas perhitungan EOQ dapat dilakukan oleh sistem. Sistem akan langsung menghitung dengan dengan menggunakan rumus EOQ. Dan hasil perhitungan sistem tersebut akan otomatis muncul saat user mengakses hasil EOQ.

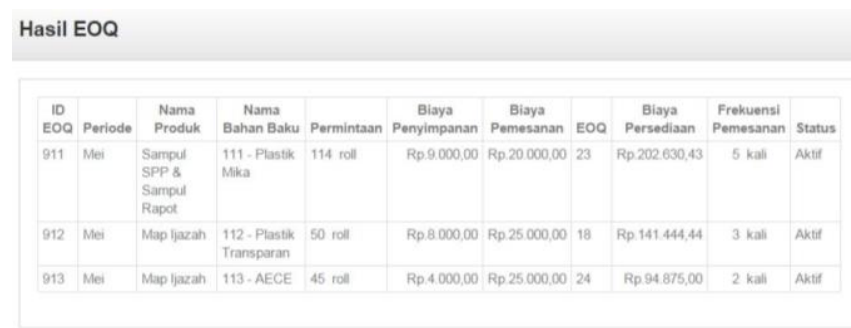

\section{Gambar 7 Pengujian Hasil EOQ}

4. Pengujian perhitungan safety stock dan reorder point

Perhitungan ini dilakukan langsung ketika bagian persediaan memasukkan data permintaan bahan baku. Sistem akan mengelola data permintaan tersebut menjadi data pemakaian maksimal, pemakaian rata-rata, hasil safety stock dan reorder point.

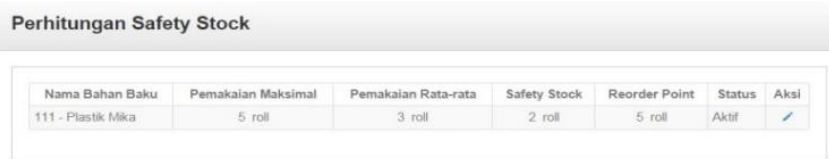

Gambar 8 Pengujian Perhitungan Safety Stock dan Reorder Point

5. Pengujian jurnal dan buku besar

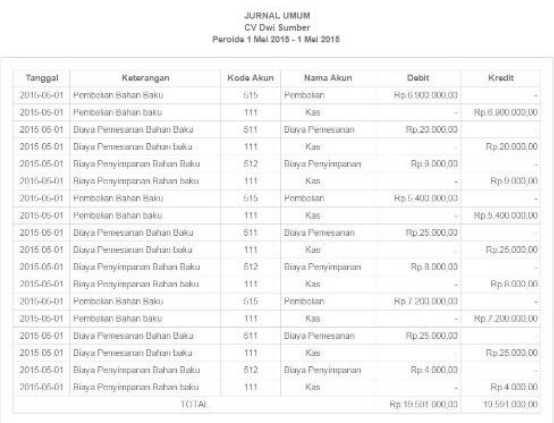

Gambar 9 Pengujian Jurnal

Akses jurnal hanya dapat dillihat oleh bagian keuangan. Data jurnaldiperoleh dari hasil transaksi pembelian, untuk data buku besar data yang diperoleh dari data jurnal.

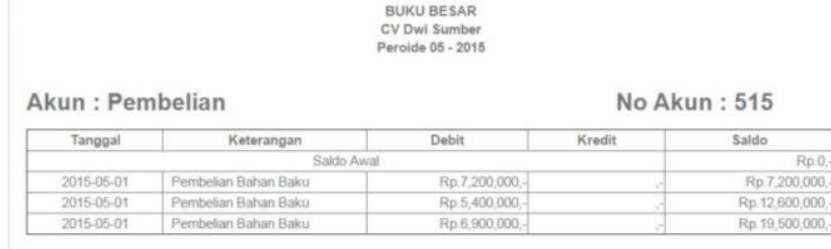

Gambar 10 Pengujian Buku Besar

Hasil perhitungan yang diperoleh dengan menggunakan aplikasi kemudian dibandingkan dengan perhitungan secara manual, untuk memastikan semua perhitungan telah sesuai dengan rumus yang digunakan. Selain itu, pihak perusahaan juga diikutsertakan dalam desain halaman aplikasi, sehingga informasi yang ditampilkan telah sesuai dengan kebutuhan perusahaan.

Dengan aplikasi ini, otomatis transaksi menyebabkan stok barang yang ada di gudang berkurang secara otomatis. Stok barang di gudang kemudian dibandingkan dengan jumlah barang minimal yang harus ada, sehingga ketika stok kurang dari yang ditetapkan, sistem menghasilkan pesan agar melakukan reorder. Jumlah barang dan frekuensi pembelian dihitung sehingga dapat menghemat biaya yang dikeluarkan untuk melakukan pemesanan. Detail transaksi juga dapat ditampilkan dalam bentuk jurnal dan buku besar sehingga memudahkan bagian keuangan untuk memonitor semua transaksi, baik secara keseluruhan maupun untuk akun-akun tertentu.

Struktur menu pada aplikasi dibuat sederhana, dengan tujuan agar dapat mengurangi kebingungan yang mungkin dialami pegawai ketika menggunakan aplikasi. Untuk mengatasi penolakan dalam menggunakan aplikasi, sebaiknya perusahaan mengadakan pelatihan singkat tentang cara penggunaan aplikasi, dan menerapkan aturan penggunaan aplikasi untuk menggantikan perhitungan secara manual yang dilakukan selam ini.

\section{KESIMPULAN}

Dari pengujian terhadap aplikasi yang dibangun, aplikasi ini dapat menghitung jumlah bahan baku yang harus dipesan dengan menggunakan perhitungan metode economic order quantity sesuai dengan pengelompokkan varian produk. Aplikasi juga dapat menghitung dan menampilkan bahan baku yang harus ada di gudang. Untuk pembuatan laporan, aplikasi dapay menmbuat serta menampilkan jurnal umum, buku besar, laporan persediaan serta laporan produksi. Dengan aplikasi ini, perusahaan dapat mengetahui jumlah pesanan yang harus dilakukan agar biaya pemesanan bahan baku optimal. Aplikasi ini juga dapay membantu pihak manajemen dalam memutuskan waktu pemesanan kembali (reorder point). 


\section{DAFTAR PUSTAKA}

[1] Nunung Nurhasanah, Richard Perdana Gunawan. Persediaan Bahan Baku Optimum dengan Metode Economic Order Quantity pada Es Chika Home Industry. Industrial and Systems Engineering Assessment Journal (INASEA), Vol 10, No 1. 2009

[2] Ruauw, Eyverson. Pengendalian Persediaan Bahan Baku (Contoh Pengendalian pada usaha Grenda Bakery Lianli, Manado). ASE - Volume 7 Nomor 1, Januari. Universitas Sam Ratulangi. 2011

[3] I Gusti Ayu Widi Astuti, Wayan Cipta, Made Ary Meitriana. Penerapan Metode Economic Order Quantity Persediaan Bahan Baku pada Perusahaan Kopi Bubuk Bali Cap "Banyuatis". Jurnal Jurusan Pendidikan Ekonomi, Vol 4, No 1. 2014

[4] Intan Maesti Gani, Analisis Peramalan Dan Pengendalian Persediaan Bahan Baku dengan Metode EOQ pada Optimalisasi Kayu di Perusahaan Purezento, Skripsi, Program Studi S1 Ilmu Administrasi Bisnis, Fakultas Komunikasi dan Bisnis, Universitas Telkom, Bandung, 2015

[5] Shalahuddin. Modul Pembelajaran Rekayasa Perangkat Lunak. Bandung: Modula, 2011.

[6] Fahmi, Irham. Manajemen Produksi Dan Operasi. Bandung: ALFABETA, 2012.

[7] Djunaeni, Moch Endang. Pengantar Manajemen Keuangan. Yogyakarta: CV Budi Utama, 2012.

[8] Samryn, L.M. Pengantar Akuntansi Mudah Membuat Jurnal Dengan Pendekatan Siklus Transaksi. Jakarta: PT RajaGrafindo Persada, 2011.

[9] Keown, Arthur J. Manajemen Keuangan. Jakarta: PT Indeks, 2010.

[10] Krismiaji. Sistem Informasi Akuntansi. Yogyakarta: Sekolah Tinggi Ilmu Manajemen YKPN, 2010. 